\title{
Research on the Establishment of Long Term Teaching Evaluation Mechanisms in Higher Vocational Colleges
}

\author{
Yu Luo \\ Kunshan Dengyun College of Science and Technology, Kunshan, Jiangsu Province, China
}

Keywords: Vocational Colleges, Teaching Evaluation, Long-Term Mechanisms.

\begin{abstract}
This paper analyzes problems in the teaching evaluation system of domestic higher vocational colleges. On the basis of domestic and foreign research, this paper discusses the establishment and improvement of long term teaching evaluation mechanisms in domestic higher vocational colleges from the aspects of personnel training orientation, quality evaluation indexes, evaluation subjects and evaluation security system under the historical background of "combining learning with working, and integrating production with education".
\end{abstract}

\section{Problems Existing in the Teaching Evaluation System of Higher Vocational Colleges under the Background of Vocational Education Transformation}

In recent years, with the enrollment expansion of colleges, the number of students declines sharply. In the era of "Internet plus", people can receive education from diversified methods, while modern colleges are faced with persistent challenges in teaching quality. Meanwhile, the economic development, as well as the industrial transformation and upgrading give rise to increasingly demands on vocational talents. Ministry of Education implements a number of policies, including transformation from academic colleges to vocational colleges, 3+2 mode, and the connection of secondary and higher vocational education, trying to build modern occupation education system. But on one hand, higher vocational colleges and application-oriented universities have different understanding on the orientation and specific training objectives of educational bodies. On the other hand, according to the research fruit of the Higher Education Evaluation Centre in the Ministry of Education, "institutions of higher learning do not pay enough attention on normal monitoring assessment, and show over reliance on experts' investigation". Therefore, the establishment of long-term teaching evaluation mechanism in higher vocational colleges is not only essential for the teaching reform of higher occupation education, but also necessary for the improvement of teaching quality in higher vocational schools.

Definition of "teaching evaluation" and "long term mechanisms". The teaching evaluation mechanisms of higher vocational colleges refer to the comprehensive evaluation of teaching quality and personnel performance of higher vocational colleges; it is a code standard based on teaching objectives and teaching quality. Through the comprehensive assessment of schools' teaching and learning situations, teaching evaluation mechanisms can be used to assess the realization degrees of schools' teaching effects and teaching goals.

Long-term mechanisms in this paper refer to normal mechanisms which always adhere to the internal teaching evaluation system under the background of deep integration of production and education. Long-term mechanisms need to carry out self assessment and self monitoring actively, trying to find and solve problems every day. Long-term mechanisms should be embedded in the daily teaching management system of higher vocational colleges, in order to strengthen the central position of teaching and guarantee the construction of quality system. Higher vocational colleges need to actively adapt to the assessment requirements of national policies, change teaching evaluation system from short-term behavior to sustainable self assessment mechanisms, and constantly improve these mechanisms with the development of higher vocational colleges. 
Research situation and development trend at home and abroad. Foreign researches on higher education evaluation have formed a relatively perfect system. Nowadays, evaluation mechanisms in the world can be divided into three groups: dominated by the government, such as France and India; mutual participation of government, school and society, such as Britain, Japan and Holland; launched by the public, such as the United States who promotes intermediary organizations to carry out quality survey and evaluation on major vocational education projects.

Through the study of the world teaching evaluation system, it can be found that the establishment of long term internal teaching evaluation mechanisms is the inevitable trend of international education assessment. At present, Britain has the most perfect internal evaluation systems; the United States pays more and more attention to the construction of internal quality assurance and evaluation systems in colleges and universities; $97.8 \%$ Japanese universities have established their own inspection and assessment committees.

In China, the project of higher vocational colleges' teaching evaluation was launched in 2003 and developed in 2004. Some scholars focus on teaching evaluation system of higher vocational colleges gradually diverts their attention from "external evaluation" to "internal evaluation supplemented by external evaluation". They believe that it is an important way to improve the quality of talent training and to strengthen the connotation construction.

At present, the academic circle mainly focuses on the long term teaching evaluation mechanism of undergraduate colleges, which have certain guidance and reference significance for the construction of long-term teaching evaluation mechanisms of higher vocational colleges. But the particularity of higher vocational colleges should also be noticed.

Existing problems in teaching evaluation system of higher vocational colleges. At present, the teaching evaluation system of higher vocational education is consisted of two parts: school evaluation and social evaluation. The subjects of school evaluation are school administration, supervision and teaching departments, who make comprehensive assessment of teaching situation from the perspective of teaching and learning evaluation. Social evaluation, on one hand, is performed by education administration authority who evaluates higher vocational colleges from personnel training objectives, teaching conditions, teaching level and educational achievement on a regular basis. On the other hand, is performed by enterprises that employ graduates from these colleges and measure their actual work performances.

Zhuan-mao Song believes that, the assessment of teaching quality is the comparison of predetermined training objectives and the actual state of teaching activities. Main factors which affect the realization of higher vocational teaching goals are basic construction of campus, teaching personnel, management level, practical training grounds, experimental equipment, books and other materials.

Comparing experts and scholars' definition and standards on teaching evaluation system and current implementation in higher vocational education, it can be found that although our country has taken up researches by the third party, enterprises only have limited cognition, participation and technical supports on information feedback in teaching assessment, and have not made impacts; the feedback evaluation of graduates cannot be made in time; social evaluation is still dominated by educational institutions. The national authority does not clear standards and definition on the orientation and talent training goals of higher vocational colleges. In the process of external evaluation, higher vocational colleges have to obey related policies; in the process of internal evaluation, they are lack of effective guidance.

On the other hand, the evaluation index setting is focused on factors affect higher vocational education, and there are few indicators used to measure the achievement of training targets. Higher occupation education is a kind of professional education based on market demand. With economic and social development, and on the basis of basic conditions of enterprises, the index system should break through the static conditions of school operation and consider the dynamic social demand. 


\section{The Establishment of Long Term Teaching Evaluation Mechanisms in Higher Vocational Colleges under the Background of Close College-enterprise Cooperation}

The premise of higher vocational teaching evaluation is the orientation of higher vocational colleges and the training target of professional talents. Colleges and universities have three major functions, namely training talents, scientific research and social service; training talents is the first priority for higher vocational education. With the continuous enrollment expansion, vocational schools are becoming increasingly important, and the transformation and upgrading of occupation education is becoming increasingly urgent. The constructing of vocational education system is facing new problems, while the development directions and orientations of higher vocational schools are becoming more and more diversified, which make the objects of teaching evaluation increasingly obscure. As the main part of teaching evaluation, the training target of professional talents is the key to guarantee the central position of teaching.

Therefore, defining the orientation of school and the targets of training talents, and implementing the central position of teaching, are the premise of promoting the teaching evaluation of higher vocational education.

The foundation of higher vocational teaching evaluation is to form an evaluation index system which focuses on talent training, and improve students' learning effects. The assessment of teaching quality is the comparison of predetermined training objectives and the actual state of teaching activities. Talents training goals and the quality of personnel training should be regarded as core elements of the evaluation mechanism; indexes on external factors such as the construction of the campus, management level, training venues, experimental equipment, books and other materials should serve as secondary elements.

Talents refer to people who have certain professional knowledge or specialized skills, and are able to engage in creative work and contribute to the society. In human resources, they are workers with greater abilities and higher qualities. Specific to enterprises, talents are people who can meet the requirements of their positions, and can contribute to the development of enterprises.

As high-quality technical and skilled personnel training institutions, higher vocational colleges should form a vocational ability oriented quality evaluation system. The evaluation of students' vocational ability should be regarded as the core of teaching evaluation.

The evaluation of occupation abilities must satisfy cognitive laws, occupation development demands and technical standards, as well as social requirements. Compared with knowledge capability assessment, occupation ability evaluation is much more difficult. So it is necessary to evaluate students' learning effects, especially in the background of vigorously promoting the occupation education, and matching major setup with industrial demand, curriculum content with occupation standard, teaching process with production process, graduation certificate with occupation qualification certificate, and occupation education with lifelong learning. It is the objective requirement of higher occupation education reform to evaluate students' comprehensive ability of decision-making, information acquisition, planning, implementation and controlling in the context of real work.

Adhering to school enterprise cooperation, changing enterprise evaluation to internal evaluation, and changing results evaluation to process evaluation, are important ways to improve the teaching evaluation reliability and validity. Meade proposed that, in Britain, the order of demand subjects who should be satisfied by university evaluation system is enterprise, industry, students, government.

Employer satisfaction is an important index to reflect the quality of talent cultivation. Now in our country, universities and government are paying more attentions to it. But it is not yet fully implemented. The main reasons include liquidity of graduates, which lead to low initiative of participation, and the feedback lag of evaluation. If the evaluation results show some problems, colleges can only improve and adjust the cultivation process of students who come into school for the next few years. 
Therefore, vocational colleges have fully realized that in order to keep pace with industrial development, vocational education must follow the road of integration production with education. Since 2010, Kunshan Dengyun College of Science and Technology has implemented the "combination of learning with working". Searching and cooperating with enterprises which are willing to cultivate talents according to practical experience, is one method to alleviate these problems.

Firstly, large-scale training will make evaluation objects relatively concentrated. Secondly, as the subjects of education, enterprises will transform assessment from external, passive evaluation to internal, active evaluation. Thirdly, students are still at school. Enterprises' feedback can be timely provided, and schools can timely adjust teaching content, which will make it easy to achieve personnel training goals.

On the basis of a stable teaching evaluation expert team, the diversification of evaluation subjects is the key to stimulate the vitality of teaching evaluation. Setting up the evaluation institutions of school teaching, establishing a stable, professional teaching evaluation team, is an important method which has been recognized by colleges and universities. Stimulating the quality consciousness of learners as subjects of education is the key of creative, sustainable development of long term teaching evaluation mechanism.

Teaching quality is the core element of students' learning experience. Teaching process is a production process which manipulates by schools and teachers. Derfel, Owen, Alessia and JM Consulting point out that, students should be an important participant in higher education evaluation. Countries such as UK, Norway and Spain have established student participation mechanisms. Based on students' view, Zhi-gang Zhou proposes that in the internal evaluation of higher vocational colleges, adding or elaborating indicators on students' learning achievement is the key of internal evaluation. Yan Zhang proposes, the establishment of a double level "students' satisfaction degree survey" is conductive to schools' education and teaching quality assessment.

On one hand, "teaching quality and student satisfaction evaluation criteria" from the "Three Subject" Collaborative Participation and Personnel Training Quality Paradigm can be used; students' experience in teaching process should be supplemented by teaching results to set overall validation index.

On the other hand, authorities should also pay great attention to objective data indexes on students' dropout rate, the arrears of tuition, professional adjustment rate, academic failure rate and corresponding causes.

Through analyzing the actual results of teaching evaluation, it can be found that apart from the reasonable degree of questionnaire, students' subjective factors can also lead to a large deviation on evaluation results. Different evaluation subjects and teaching objectives will lead to different tendencies of questionnaire. Objective data index is the externalization of students' overall satisfaction degree, which can reflect the overall level of college construction and teaching construction better.

As the leading party of teaching, teachers' satisfaction is closely related to their job initiative, job burnout and teaching efficacy. In addition to exerting pressure on improving teaching quality, teaching evaluation mechanism should also try to stimulate teachers' internal motivations and release their potential abilities.

Improving the information management system, and forming a complete loop through decision-making, management execution and monitoring and diagnosis, can guarantee the long-term operation of internal evaluation mechanisms. In the process of teaching, leaders' implementation on feedback problems and decisions, the tracking and monitoring of implementation, and the real-time data feedback on information platform, form a complete loop. Any problems in any links will weaken the overall efficiency of the teaching evaluation mechanism.

At present, functional departments of most colleges have independent information platforms, and do not have a unified statistic standard. The reliability and validity of data are low.

The construction of digital campus should start from a global view, and match the evaluation system of higher educational authorities. It should not only meet the demands of management and 
execution, but also form unified monitoring and diagnosis data, in order to warn about problems and provide the basis for decision-making. It will combine evaluation with daily work, change work performance into data directly, offer effective guidance through data monitoring, and change from passive assessment to active self assessment.

\section{Acknowledgements}

Fund Project: This paper is supported by Foundation for Planning Projects on Science of Education of the Twelfth Five-Year Plan of Jiangsu Province. Project No: D/2015/03/087.

\section{References}

[1] Z.B. He, The establishment of long-term teaching evaluation mechanisms in higher education institutions in the post evaluation era, J. China University Teaching. 3(2009) 69-71.

[2] C.S. Zhu, Grasp the policy of "twenty characters" and establish long-term teaching evaluation mechanisms, J. China Higher Education. 9 (2006).

[3] A.Z. Pan, Discussion on the establishment of long-term teaching evaluation mechanisms in local universities, J. China University Teaching. 2(2007) 71-72.

[4] Y. Wu, Construction of teaching quality evaluation system in higher vocational colleges, J. Modern Education Science. 2(2003) 51-54

[5] F.M. Xu, Thinking and exploration about the establishment of long-term teaching evaluation mechanisms, J. China Higher Education. 1(2007) 40-42. 